\title{
Cdk2 acts upstream of mitochondrial permeability transition during paclitaxel-induced apoptosis
}

\author{
Xiao-Xi Guo ${ }^{1}$, Hanna Kim², Yang Li ${ }^{1}$, Hyungshin Yim $^{2}$, Seung Ki Lee ${ }^{2 凶}$, Ying-Hua Jin ${ }^{1 凶}$ \\ ${ }^{1}$ Key Laboratory for Molecular Enzymology \& Engineering of the Ministry of Education, Jilin University, Changchun 130012 , \\ China \\ 2 Division of Pharmaceutical Biosciences, Research Institute for Pharmaceutical Sciences, College of Pharmacy, Seoul National \\ University, Seoul 151-742, Korea \\ $₫$ Correspondence: sklcrs@plaza.snu.ac.kr (S. K. Lee), yhjin@jlu.edu.cn (Y.-H. Jin) \\ Received March 16, 2011 Accepted June 27, 2011
}

\begin{abstract}
Sequential activation of cyclin-dependent kinases (Cdks) controls mammalian cell cycle. Here we demonstrate that the upregulation of cyclin-dependent kinase 2 (Cdk2) activity coincides with the loss of mitochondrial membrane potential (MMP) in paclitaxel-induced apoptosis. Ectopic expression of the dominant negative Cdk2 (Cdk2-dn) and a specific Cdk2 inhibitor, p21 WAF1/CIP1, effectively suppresses the loss of MMP, the release of cytochrome c, and subsequent activation of caspase- 3 in paclitaxel-treated cells. Whereas forced activation of Cdk2 by overexpression of cyclin A dramatically promotes these events. We further show that $\mathrm{Cdk} 2$ activation status does not interfere with a procedure that lies downstream of cytochrome c release induced by Bax protein. These findings suggest that Cdk2 kinase can regulate apoptosis at earlier stages than mitochondrial permeability transition and cytochrome c release.
\end{abstract}

KEYWORDS apoptosis, cyclin-dependent kinase 2, cytochrome c release, mitochondrial membrane potential, paclitaxel

\section{INTRODUCTION}

The mammalian cell cycle is governed by the sequential activation of cyclin-dependent kinases (Cdks) (Bruce et al., 2001). Progression through $G_{1}$ and entry into $S$ phase are regulated by $\mathrm{Cdk} 2$ complexed with cyclin $\mathrm{A}$ and cyclin $\mathrm{E}$, and the $G_{2} / M$ transition is driven by $C d c 2$ complexed with cyclin $B$ (Kaldis and Aleem, 2005).
An accumulating body of evidence suggests that Cdks, which are critical cell cycle regulators, also play important roles in regulating the progression of apoptosis. Cdc2 activity is frequently upregulated in $\mathrm{G}_{2} / \mathrm{M}$ phase arrest-associated apoptosis induced by paclitaxel, vincristine (Stewart et al., 1999), or death receptor mediated apoptosis (Zhou et al., 1998). Cdk1/cyclin B1 activity shields human cells against extrinsic death stimuli (Matthess et al., 2010). Cdk2 activation is mainly detected in apoptotic cells that exhibit $\mathrm{G}_{1} / \mathrm{S}$ phase arrest, as observed in ultraviolet irradiation-treated mesangial cells (Hiromura et al., 2002), etoposide-induced human leukemic cells (Choi et al., 2007; Bastin-Coyette et al., 2011), growth factor-deprived HUVEC cells (Levkau et al., 1998), G-Rh2-induced human hepatoma cells (Jin et al., 2000), panaxadiol-induced SK-HEP-1 cells (Jin et al., 2003). In previous reports, we showed that Cdk2 but not Cdc2 is selectively up-regulated and this upregulation is required for the induction of apoptosis in several cancer cell lines, including SK-HEP-1 cells and HeLa cells induced by treatment with ginsenoside-Rh2 (G-Rh2) (Jin et al., 2000) or panaxadiol (Jin et al., 2003). The upregulation of Cdk2 activity during apoptosis has been suggested to result from the elimination of the Cdk2 inhibitor protein, p21 WAF1/CIP1 from the cyclin A-Cdk2 complex by proteolysis (Jin et al., 2000). However, the signaling mechanism responsible for linking Cdk2 with downstream apoptosis pathway is largely unknown.

Two distinct pathways for triggering apoptosis have been delineated (Shi, 2002; Riedl and Shi, 2004). In the first, ligandbound membrane receptors such as CD95/Fas/APO-1 recruit and oligomerize the adaptor protein and procaspase-8, followed by caspase-8 processing (Salvesen and Dixit, 
1999). In the second pathway, apoptosis is triggered by a change in mitochondrial permeability that results in the release of cytochrome c (Li et al., 2000; Garrido et al., 2006; Caroppi et al., 2009). Once cytochrome c binds its cytosolic partner Apaf-1, the human homologue of the apoptotic protein CED-4, to form an oligomeric Apaf-1cytochrome c complex in an ATP/dATP-dependent manner. This multimeric complex, referred to as the apoptosome, recruits the initiator caspase- 9 and promotes its autoactivation. Activated caspase- 9 subsequently triggers a caspase cascade by processing downstream effector caspases, caspase-3, -6, and-7 (Shi, 2002; Pradelli et al., 2010). There have been several lines of evidence suggesting that the caspase activation cascade that is mediated through the mitochondria can be regulated by multiple regulatory mechanisms. Firstly, Bcl-2 family proteins act as gatekeepers in controlling the release of cytochrome $\mathrm{c}$ from mitochondria (Breckenridge and Xue, 2004; Willis and Adams, 2005; Chipuk and Green, 2008). Pro-apoptotic Bcl-2 proteins induce the mitochondrial cytochrome $c$ release whereas overexpressed anti-apoptotic Bcl-2 proteins prevent it (Placzek et al., 2010). Secondly, the process of apoptosome formation and caspase- 9 autoactivation can be negatively regulated by Hsp-70 and Hsp-90, which prevents the oligomerization of Apaf-1 and its association with procaspase-9 (Beere et al., 2000; Pandey et al., 2000; Saleh et al., 2000; Garrido et al., 2006). Thirdly, activations of caspase- $9,-3$ and -7 are negatively regulated by inhibitor of apoptosis (IAP) family proteins (Liston et al., 2003; Chang and Schimmer, 2007), which directly bind and inhibit these caspases. Moreover, IAPs-mediated inhibition of caspase activity is relieved by the mitochondrial proapoptotic protein, Smac/Diablo (Du et al., 2000; Wu et al., 2007). Paclitaxel is effective in the treatment of several tumor types, particularly ovarian and breast cancers (Rowinsky and Donehower, 1995; Marupudi et al., 2007). Its anti-tumor activity is related to its effect on microtubule stabilization, resulting in cell cycle arrest in the $G_{2} / M$ phase (Hunt, 2009) and ultimately, apoptosis in some cell types (Schiff et al., 1979). Activation of the Apaf-1caspase-9 complex appears to be the primary pathway mediating apoptotic progression in paclitaxel-induced cells (André et al., 2000; Djeu and Wei, 2009). Bcl-2 is phosphorylated in paclitaxel-treated HeLa cells, but this phosphorylation is associated with cell cycle arrest but not with apoptosis (Ling et al., 1998).

In the present study we investigated whether the upregulation of Cdk2 activity is also involved in $\mathrm{G}_{2} / \mathrm{M}$ phase arrestassociated apoptosis (as does Cdc2) and if so, which level in mitochondrial mediated caspase activation pathway is linked with Cdk2 activity. Here we show that both Cdc2 and Cdk2 kinase activities are markedly upregulated, and the kinetic profile of Cdk2 activation more closely coincides with apoptosis process including mitochondrial membrane depolarization, caspase- 3 activation and apoptotic body formation than that of Cdc2. Selective inhibition of Cdk2 activity by the expression of the dominant negative version of Cdk2 (Cdk2$\mathrm{dn}$ ), or $\mathrm{p} 21^{\text {WAF } 1 / C I P 1}$, prevents the mitochondrial permeability transition, cytochrome c release, and subsequent caspase-3 activation, indicating that the upregulation of Cdk2 activity is essential for the mitochondrial permeability transition in paclitaxel induced apoptosis. We also provide evidence that Cdk2 kinase activity in paclitaxel-induced apoptotic cells is essential for the upstream events of the mitochondrial mediated apoptotic pathway, but not for subsequent events of the mitochondrial permeability transition stage.

\section{RESULTS}

\section{Cell cycle arrest in the $G_{2} / M$ phase precedes the mitochondrial membrane depolarization during paclitaxel-induced apoptosis in HeLa cells}

To investigate whether cell cycle arrest in the $G_{2} / M$ phase functionally associates with apoptotic progression in paclitaxel-treated HeLa cells, we examined the kinetics of cell cycle progression and apoptotic body formation by flow cytometry analysis. Flow cytometry analysis showed that the arrest of cells at $G_{2} / M$ was obviously detected as early as $3 \mathrm{~h}$, and rapidly accumulated in the first $12 \mathrm{~h}$ after paclitaxel treatment; the percentage of cells in the $\mathrm{G}_{2} / \mathrm{M}$ phase reached $61 \%$, and then gradually reduced, while the proportion of cells in the $G_{1}$ phase decreased accordingly in the first $12 \mathrm{~h}$ (Fig. $1 A$ and 1D). Furthermore, the frequency of sub- $G_{1}$ cells, which represent apoptotic bodies, was observed to be about $3 \%$ after $12 \mathrm{~h}$, with a further $7 \%$ increase after $30 \mathrm{~h}$ incubation with paclitaxel (Fig. $1 \mathrm{~A}$ and 1E). Because apoptotic body formation is a late event in the apoptosis process, we next examined the kinetics of apoptotic events such as changes in cell morphology, depolarization of the mitochondrial membrane, and activation of caspase- 3 activity. Cell rounding and membrane blebbing occurred sequentially during the $24 \mathrm{~h}$ following paclitaxel treatment (Fig. 1B). To determine the change of mitochondrial membrane potential, we stained cells with a mitochondrion-specific cationic dye, Mitocapture, and observed that the mitochondrial permeability transition was detected as early as $9 \mathrm{~h}$ after paclitaxel treatment (Fig. 1D). Caspase-3 activity was detectable in cell lysates at $12 \mathrm{~h}$ posttreatment, followed by a gradual and marked elevation which was depressed by caspase inhibitor z-VADfmk (Fig. 1E). Immunoblot analysis showed that cleavage of the endogenous caspase- 3 substrate, PARP, to an $85-\mathrm{kDa}$ product also occurred with kinetics similar to that of caspase-3 activation (Fig. 1E and 2A). These results indicated that paclitaxel induces cell cycle arrest at $G_{2} / M$ phase at early stages of apoptosis, followed by the loss of MMP, activation of death effector caspases leading to apoptosis.

Thus, apoptosis in paclitaxel-induced HeLa cells appears 
A

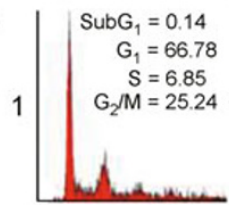

$\mathrm{Oh}$

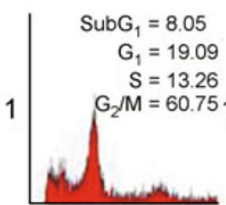

$18 \mathrm{~h}$

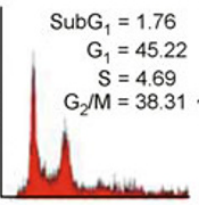

$6 \mathrm{~h}$

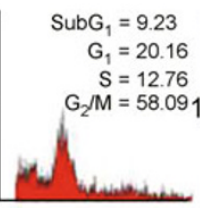

$24 \mathrm{~h}$

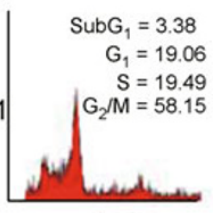

$12 \mathrm{~h}$

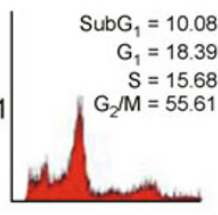

$30 \mathrm{~h}$

D

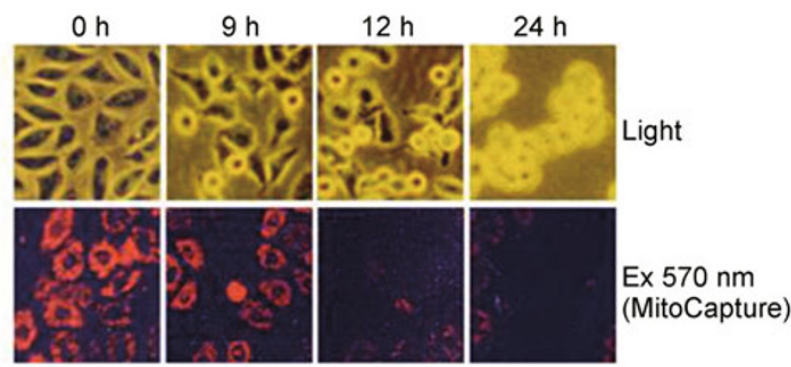

B

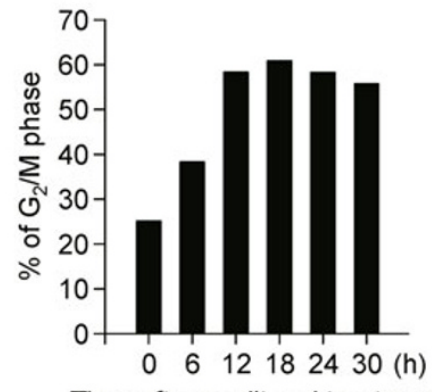

Time after paclitaxel treatment
C

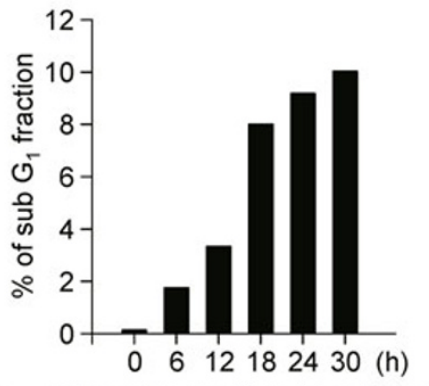

Time after paclitaxel treatment

E

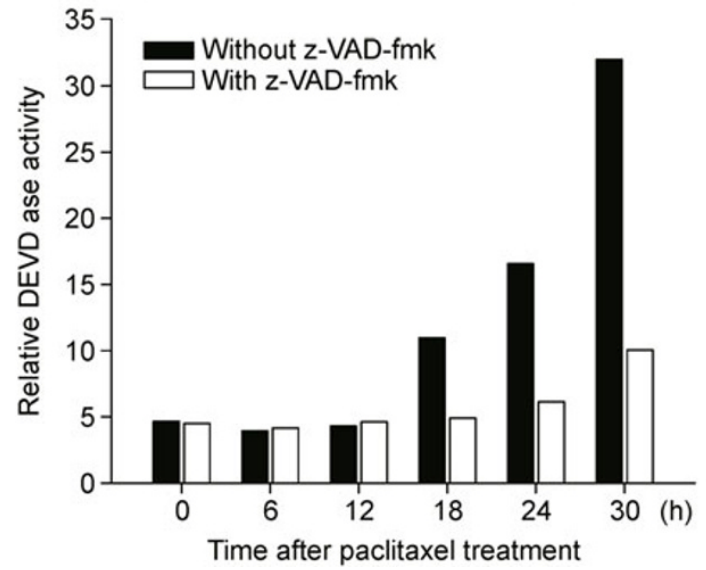

Figure 1. Paclitaxel-induced apoptosis in HeLa cells occurs after cell cycle arrest in $\mathbf{G}_{2} / \mathbf{M}$ phase. (A) HeLa cells were treated with paclitaxel $(80 \mathrm{nmol} / \mathrm{L})$ for indicated times and flow cytometric analysis was carried out as described in MATERIALS AND METHODS. (B) The proportion of cell populations in the $G_{2} / M$ phase was calculated and is represented by a histogram. (C) The proportion of cell populations in the subG ${ }_{1}$ fraction was calculated and is represented by a histogram. (D) Cells stained with Mitocapture were photographed by phase contrast microscopy $(\times 100)$ (upper panel) or fluorescence microscopy $(\times 100)$ (lower level). (E) HeLa cells were treated with paclitaxel $(80 \mathrm{nmol} / \mathrm{L})$ in the presence or absence of $z$-VAD-fmk $(30 \mu \mathrm{mol} / \mathrm{L})$ for indicated times. Cell lysates were prepared and the same amounts of proteins of each sample were analyzed for caspase-3 (DEVDase) cleavage activity using cell-free protease assay as described in MATERIALS AND METHODS.

to be functionally linked to the $\mathrm{G}_{2} / \mathrm{M}$ phase arrest and depolarization of mitochondrial membrane potential.

\section{Both cyclin B-Cdc2 and cyclin A-Cdk2 kinase activities are up-regulated during paclitaxel-induced apoptosis}

We next examined if cyclin-Cdk activities, which are precisely regulated in a cell cycle-specific manner, might be perturbed in the early stages of apoptosis in paclitaxel-treated HeLa cells. Immuno-complex kinase assays showed that Cdc2 kinase activity is detectably up-regulated as early as $3 \mathrm{~h}$ after paclitaxel treatment, with a marked elevation persisting thereafter (Fig. 3C). Upregulation of Cdc2 kinase activity preceded PARP cleavage, which was first detectable between $12 \mathrm{~h}$ and $15 \mathrm{~h}$, but the two events were coincident for $24 \mathrm{~h}$ after treatment. These results indicated that Cdc2 activity remained high levels during the $\mathrm{G}_{2} / \mathrm{M}$ arrest and apoptotic progression.

Interestingly, Cdk2 activity was also significantly elevated, and the activation profiles differed from those of Cdc2 activity in the etoposide-induced cells. Cdk2 kinase activity was elevated at $6 \mathrm{~h}$ and remained high until $15 \mathrm{~h}$ post-treatment, and thereafter the kinase activity gradually declined (Fig. 2B). Thus, the upregulation of Cdk2 kinase activity coincided well with the kinetics of the initiation but not with the progression kinetics of apoptosis, while Cdc2 kinase activation occurred much earlier than the initiation process although the activation profile after $12-15 \mathrm{~h}$ post-treatment paralleled with the progression kinetics of apoptosis in paclitaxel-treated cells (Fig. 2). Increases in cyclin A and cyclin B levels also coincided with the upregulation of Cdk2 and Cdc2 activities, 
A $\quad 0 \quad 3 \quad 6 \quad 9012151821242730$ (h)

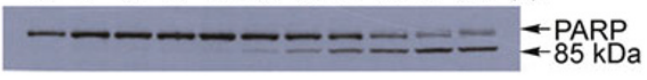

B $\quad$\begin{tabular}{llllllllllll}
\hline & 3 & 6 & 9 & 12 & 15 & 18 & 21 & 24 & 27 & 30 & (h)
\end{tabular}

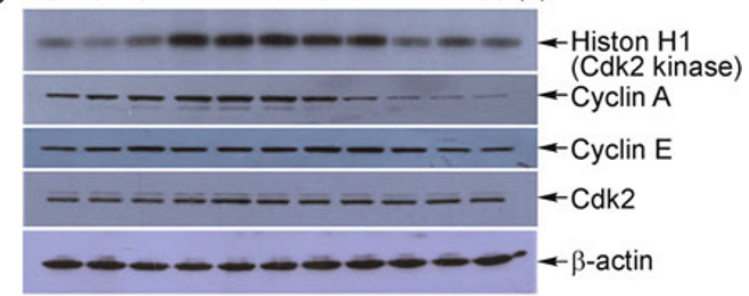

C $\begin{array}{lllllllllllll}0 & 3 & 6 & 9 & 12 & 15 & 18 & 21 & 24 & 27 & 30 & (\mathrm{~h})\end{array}$

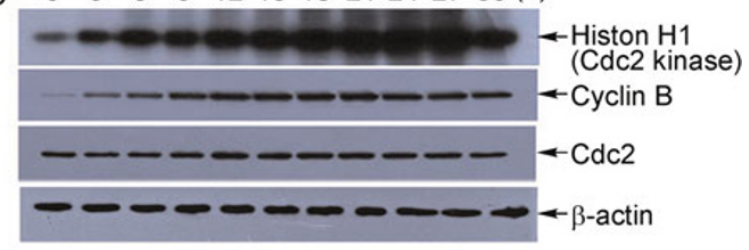

Figure 2. Both cyclin B-Cdc2 and cyclin A-Cdk2 kinase activities are up-regulated during paclitaxel-induced apoptosis. (A-C) Whole cell extracts were prepared from HeLa cells treated with paclitaxel $(80 \mathrm{nmol} / \mathrm{L})$ for indicated times and resolved by SDS-PAGE and analyzed by immunoblotting using specific antibodies against PARP, cyclin A, Cdk2, cyclin B, cyclin $E, C d c 2$ and $\beta$-actin. Cdk2 (B) and Cdc2 (C) immune complex kinase assay was performed using histone $\mathrm{H} 1$ as a substrate as described in MATERIALS AND METHODS.

respectively (Fig. $2 \mathrm{~B}$ and $2 \mathrm{C}$ ), indicating that the changes in these kinase activities may be attributed, at least in part, to the elevated levels of their respective regulatory partners.

Apoptotic cell death can be prevented by the selective inhibition of either Cdk2 kinase activity in paclitaxeltreated cells

We then examined if the upregulation of Cdk2 kinase activity might be functionally linked to the initiation processes of apoptosis that are associated with the mitochondrial functions. To regulate Cdk2 activity in the target cells, we transiently transfected HeLa cells with expression vectors that encoded cyclin A, Cdk2-dn, or p21 WAF1/CIP. And also Bcl2 cDNA was separately transfected in the cells to test if apoptosis-associated activation of Cdk2 activity is functionally linked to the mitochondrion-dependent processes of apoptosis. Cyclin A-Cdk2 kinase activity increased efficiently in the cyclin A transfectant and decreased significantly in the Cdk2-dn or p21 WAF1/CIP1 expressed cells in a DNA-dose dependent manner (Jin et al., 2000). Using these transfected cells, we examined apoptosis progression after paclitaxel treatment. The percentage of apoptotic cell death was determined by counting the number of cells showing cell rounding and membrane blebbing. In addition, transfected cells were differentiated from untransfected cells by cotransfection with the green fluorescence protein expression vector pCMV-GFP. A kinetic analysis showed that percentages of cells with apoptotic morphology were much higher among transfectants expressing cyclin A ( $82 \%$ after $18 \mathrm{~h}$ ) than those among mock transfectants $(58 \%$ after $18 \mathrm{~h})$ after treatment with paclitaxel (Fig. 3A and 3B).

Interestingly, the apoptotic cell populations were markedly decreased in cells expressing Cdk2-dn or $\mathrm{p} 21^{\text {WAF } 1 / C I P 1}$ as compared with those in the mock or cyclin A expressed cells, and the decreased levels were similar to those in the Bcl-2 expressed cells until $18 \mathrm{~h}$ after paclitaxel treatment (Fig. 3B).

Our results showed that the proportions of cells with apoptotic cell morphology and expressing Cdk2-dn, or p $21^{\text {WAF } 1 / C I P 1}$ were within $16 \%-22 \%$ over the course of $24 \mathrm{~h}$ after treatment. In contrast, the proportion of apoptotic cells in $\mathrm{Bcl}-2$ expressed cells increased up to $43 \% 24 \mathrm{~h}$ after paclitaxel treatment. Under the same conditions, apoptotic cell populations in mock-transfected cells increased by more than $80 \%$ over the course of $24 \mathrm{~h}$ after treatment with paclitaxel. Thus, the suppressive effects of apoptosis in cells by expressing Cdk2-dn or p21 ${ }^{\text {WAF1/CIP1 }}$ were even higher than those in cells by expressing $\mathrm{Bcl}-2$, a mitochondrion stabilizing protein. These results indicated that the Cdk2 kinase activity dependent regulation of apoptosis process is likely to occur at earlier stages than those regulated by $\mathrm{Bcl}-2$ protein.

To provide further evidence supporting this idea, we next determined caspase- 3 activity in transfected cells after treatment with paclitaxel. The results indicated that caspase-3 activity, as expected, greatly elevated in cyclin A transfectants but markedly decreased in cells expressing Cdk2-dn, $\mathrm{p} 21^{\text {WAF1/CIP1 }}$ or Bcl-2, as compared with the activity in paclitaxel-treated mock transfectants (Fig. 3C). These results implicated that Cdk2 activity may play a critical role in the initiation processes of apoptosis

The paclitaxel-induced mitochondrial permeability transition is effectively blocked by selectively inhibiting Cdk2 kinase activity

To examine whether Cdk2 kinase activity might involve in the regulation of the mitochondrial permeability transition and subsequent release of cytochrome $\mathrm{c}$ from mitochondria, we utilized a mitochondrion-specific cationic dye, Mitocapture, to evaluate changes in the mitochondrial membrane potential in cells overexpressing cyclin A, Cdk2-dn, p21 ${ }^{\text {WAF1/CIP1 }}$, or Bcl-2 after treatment with paclitaxel (Fig. 4A). The transfected cells were also differentiated from the untransfected cells by cotransfecting the cells with the GFP-expressing plasmid. After treatment with paclitaxel, $42 \%$ of mock-transfected cells underwent depolarization of the mitochondrial membrane, while the ectopic expression of cyclin A further increased this 
A

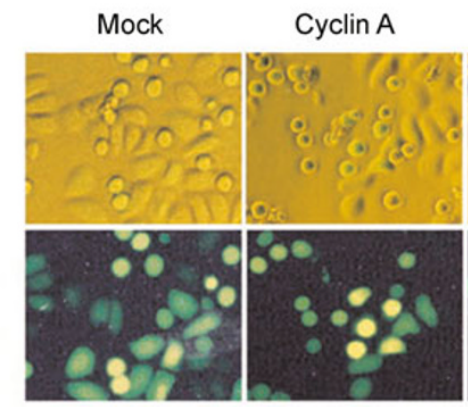

Cdk2-dn

p21 WAF1

$\mathrm{Bcl}-2$
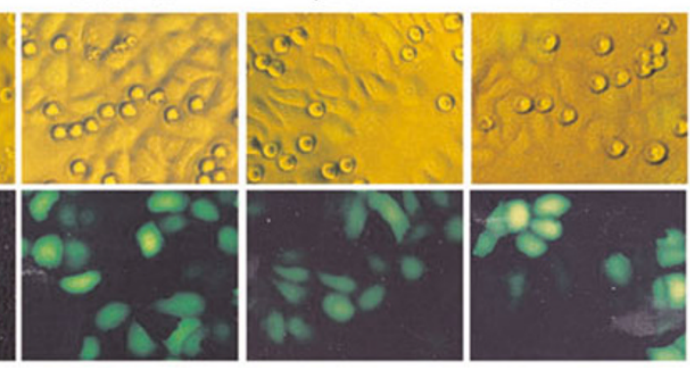

B

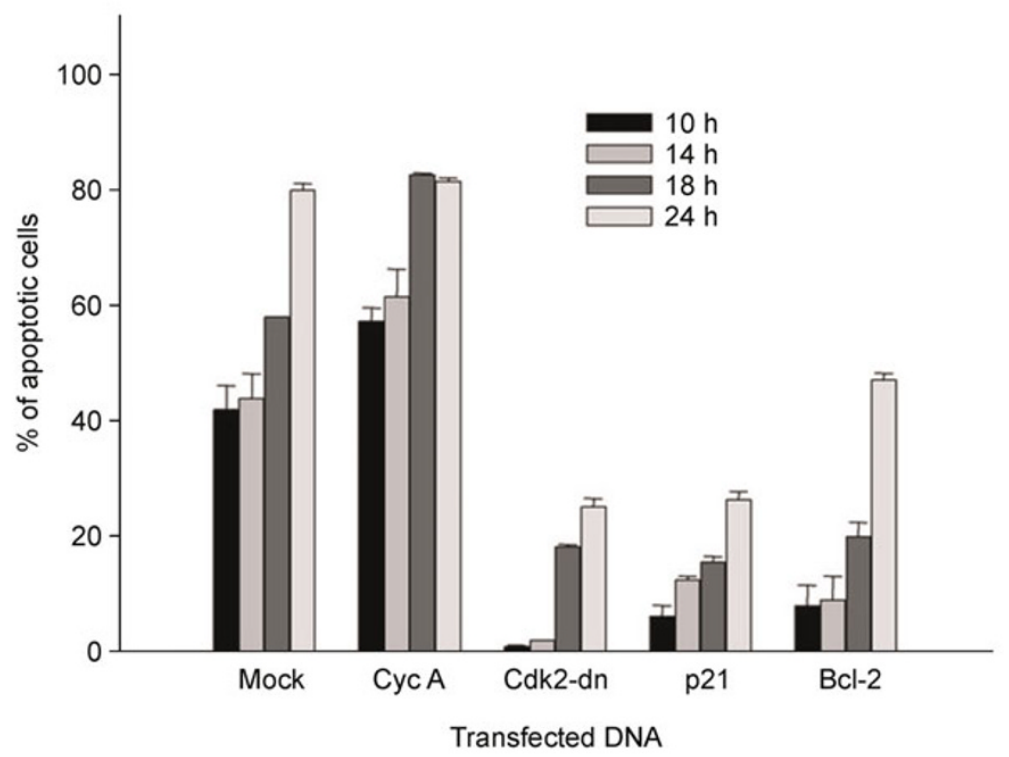

C

D
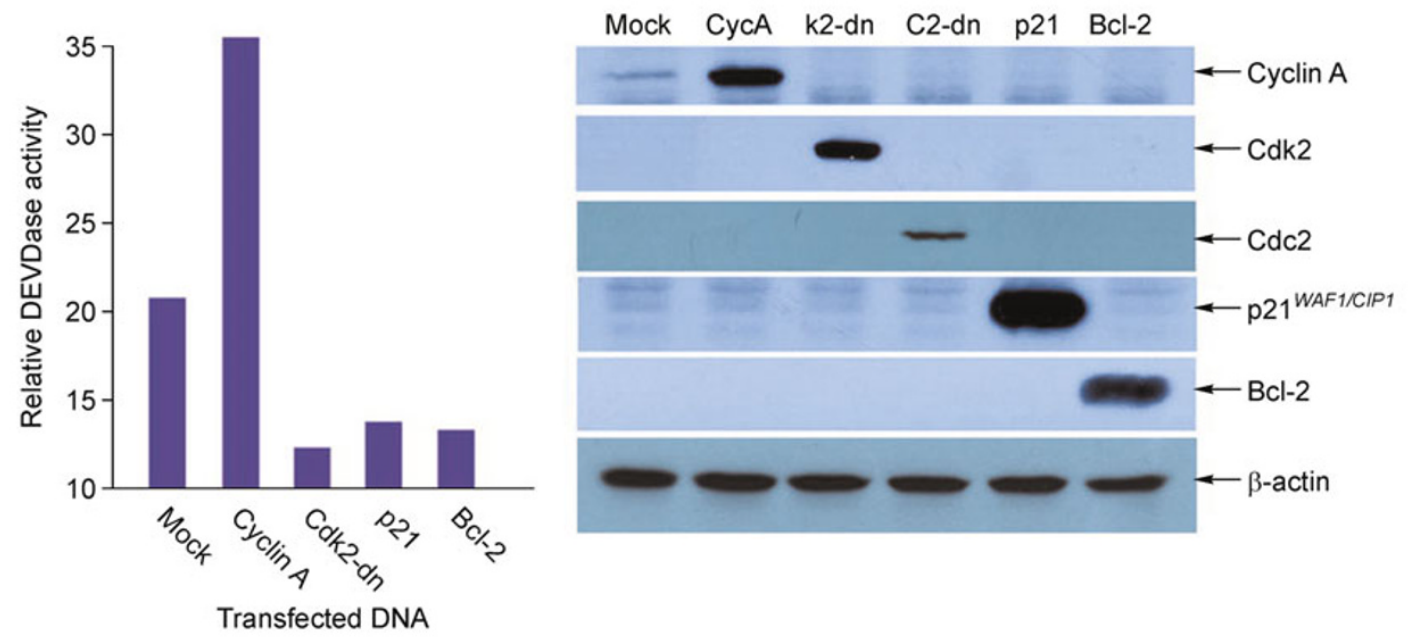

Figure 3. Ectopic expression of Cdk2-dn and p21WAF1/CIP1 suppresses paclitaxel-induced apoptosis, while that of cyclin A accelerates apoptosis. HeLa cells were cotransfected with $1.5 \mu \mathrm{g}$ of pCMV, pCMV-cyclin A, pCMV-cdk2-dn, pCMV$\mathrm{p} 21^{\text {WAF1/CIP1 }}$, or pCMV-Bcl-2 and $0.5 \mu \mathrm{g}$ of pCMV-GFP. Twenty-four hours after transfection, the cells were induced to undergo apoptosis by incubation with paclitaxel $(80 \mathrm{nmol} / \mathrm{L})$ for $10,14,18$, and $24 \mathrm{~h}$, respectively. (A) Bright-field and GFP fluorescence of the same field $(\times 100)$ of transfected cells, which were incubated with paclitaxel for $14 \mathrm{~h}$. (B) GFP expressing cells with blebbing or normal morphologies were counted. The average numbers in five different fields from two independent experiments are shown. (C) Caspase-3 activity in transfected cells after treatment with paclitaxel for $14 \mathrm{~h}$ was determined using Ac-DEVD-AFC as a substrate. (D) Immunoblotting analysis of the levels of cyclin A, Cdk2-dn, p21 WAF1/CIP1, Bcl-2 and $\beta$-actin expressed in the transfectants. 
A

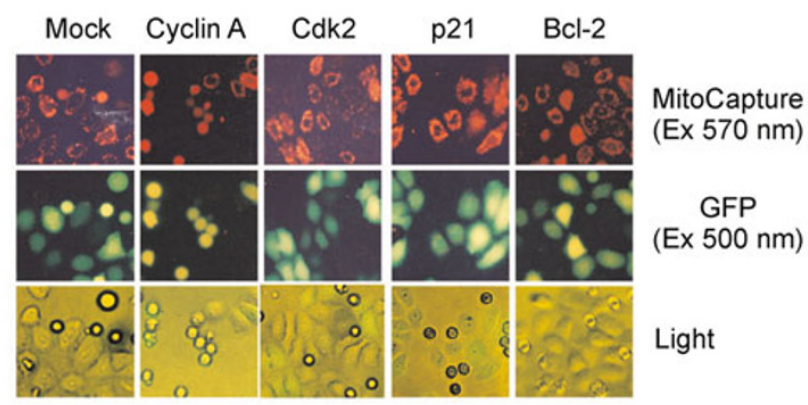

C

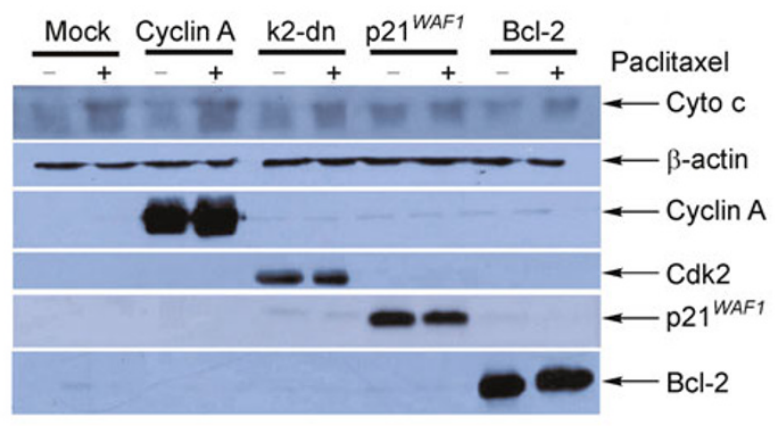

E

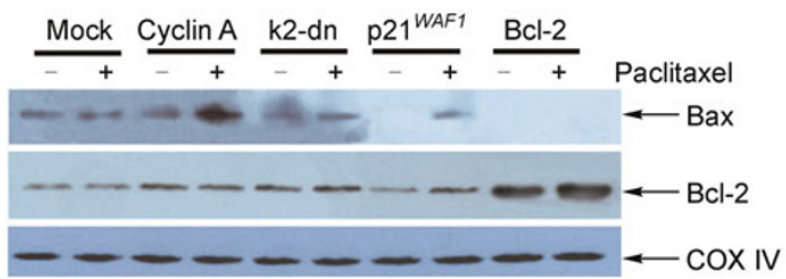

B
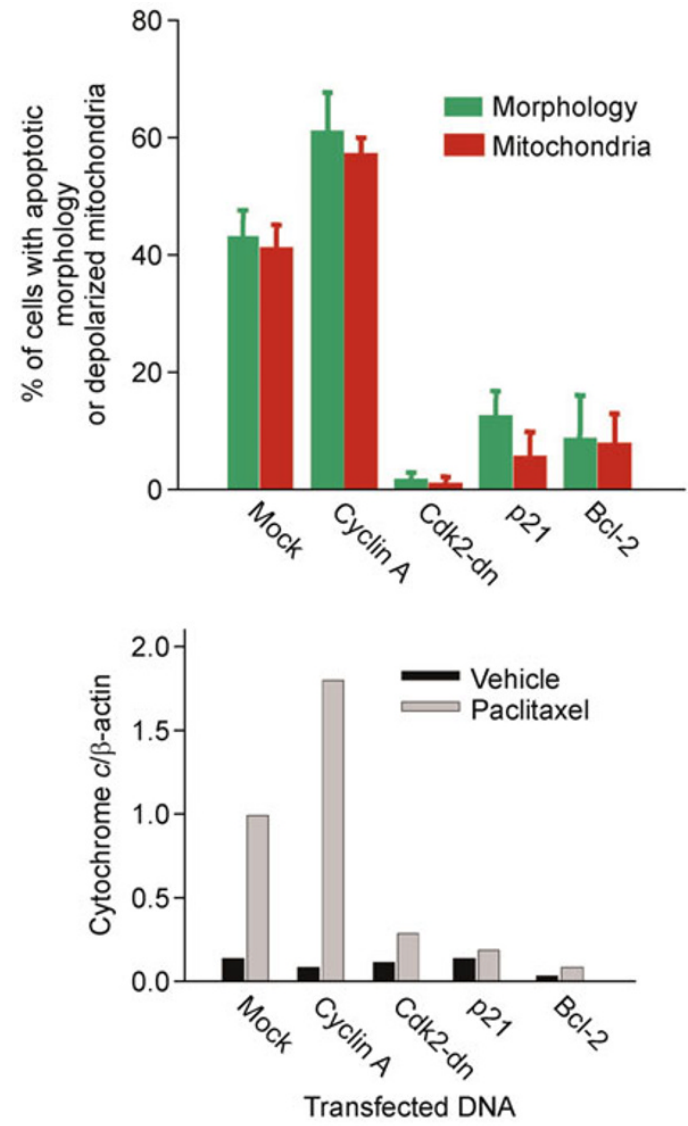

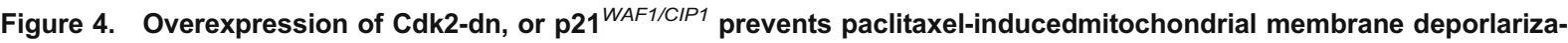
tion, cytochrome $c$ release, mitochondrial bax upregulation and apoptosis progression. (A) HeLa cells were cotransfected with $1.5 \mu \mathrm{g}$ of pCMV, pCMV-cyclin A, pCMV-Cdk2-dn, pCMV-p2 $21^{\text {WAF1/CIP1 }}$ or pCMV-Bcl-2 and $0.5 \mu \mathrm{g}$ of pCMV-GFP. Twenty-four hours after transfection, the cells were induced to undergo apoptosis by incubation with paclitacel $(80 \mathrm{nmol} / \mathrm{L})$. After $14 \mathrm{~h}$ of incubation with paclitaxel, the cells were stained with MitoCapture (CalBiochem) and examined by fluorescence microscopy (Olympus). Upper level: red fluorescence indicating mitochondrion staining; middle level: GFP fluorescence, and lower level: brightfield of the same field cells. (B) Transfected GFP expressing cells with normal mitochondria or deporlarized mitochondria (red bar), blebbing or normal morphologies (green bar) were counted. The results show the average numbers in five different fields from two independent experiments. (C) Cytosolic cytochrome $c$ and $\beta$-actin were determined by immunoblotting analysis (upper panel), protein levels of cyclin A, Cdk2-dn p2 ${ }^{\text {WAF1/CIP1 }}$ and Bcl-2 in transfercted cells (lower panel). (D) The protein levels of cytochrome $\mathrm{C}$ and $\beta$-actin in $(C)$ were densitometically measured and their ratios are presented. (E) Mitochondrial Bax, Bcl-2, and COX IV were determined by immunoblot analysis.

proportion to $58 \%$ (Fig. $4 \mathrm{~A}$ and $4 \mathrm{~B}$ ). In contrast, the mitochondrial depolarization was effectively blocked in paclitaxel-treated cells expressing Cdk2-dn, p21 WAF1/CIP1, or Bcl-2 (Fig. 4B). Moreover, the results indicated that both apoptotic events were more effectively prohibited in cells expressing Cdk2-dn (by about $2 \%$ ) than in cells expressing p $21^{\text {WAF } 1 / C I P 1}$, or Bcl-2 (6\%-8\%). We then examined cytochrome $\mathrm{c}$ release from mitochondria to cytoplasm in paclitaxel-treated transfected cells. Immunoblot analysis showed that cytosolic cytochrome c levels were markedly decreased in cells expressing Cdk2-dn, p21WAF1/CIP1, or $\mathrm{Bcl}-2$, but significantly increased in cells expressing cyclin A (Fig. 4C and 4D). On the other hand, we observed upregulated mitochondrial Bax after paclitaxel treatment in cells expressing cyclin $A$, but not in cells expressing p21 ${ }^{\text {WAF } 1 / C I P 1}$, or Bcl-2 (Fig. 4E). Cyclin A and Cdk2 were not detected in mitochondrial fractions (data not shown). These findings strongly suggested that Cdk2 kinase plays an 
A
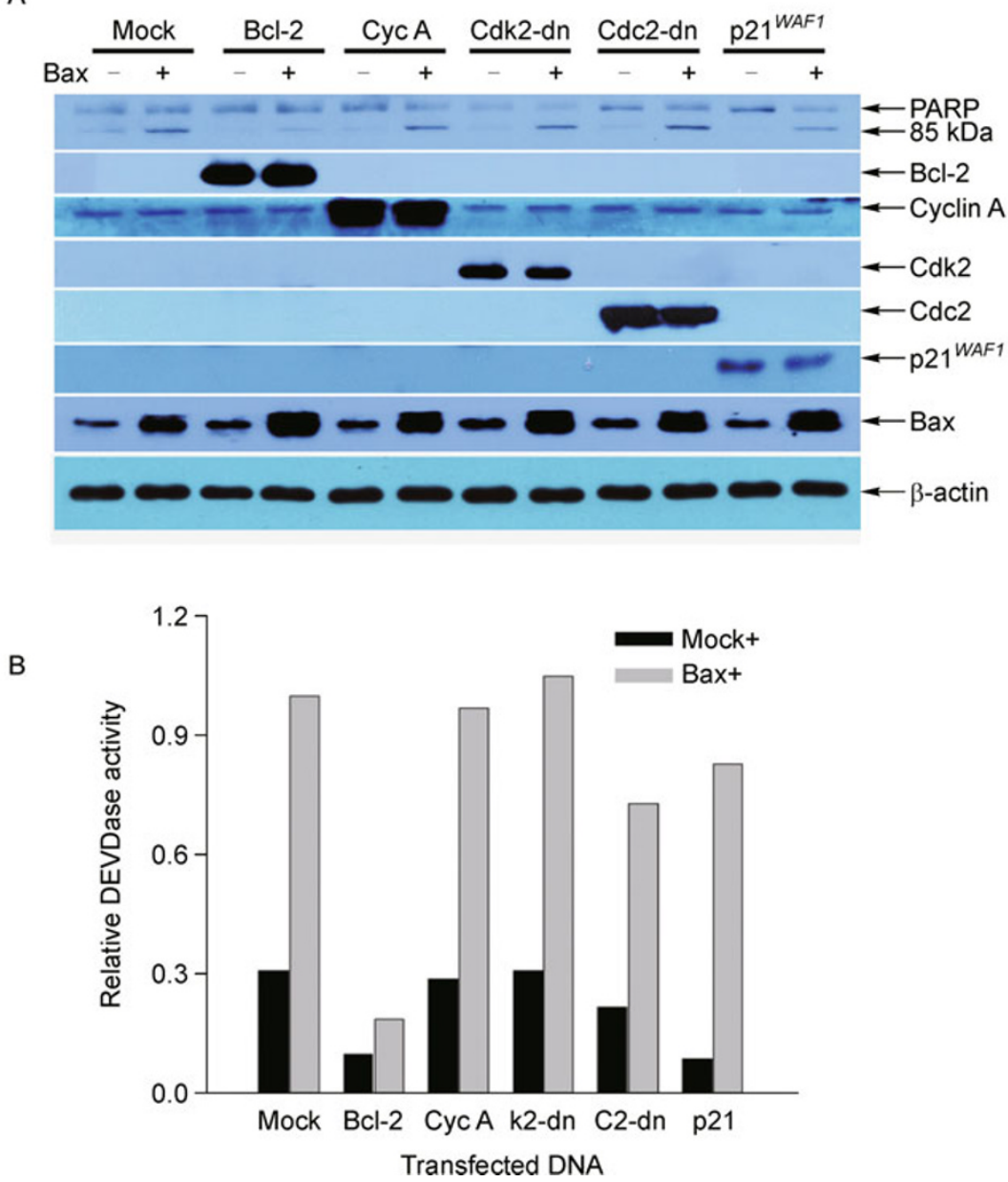

Figure 5. Overexpression of cyclin A, Cdk2-dn, and p21 ${ }^{W A F 1 / C I P 1}$ does not inhibit Bax-induced PARP cleavage and caspase-3/7 activation. (A) HeLa cells were cotransfected with $1.5 \mu \mathrm{g}$ of pCMV, pCMV-Bcl-2, pCMV-cyclin A, pCMV-Cdk2-dn, pCMV-Cdc2-dn, pCMV-p21 WAF1/CIP1 with or without $0.5 \mu \mathrm{g}$ of pCMV-Bax. Twenty-four hours after transfection, the cells were harvested and analyzed using specific antibodies against PARP, Bcl-2, cyclin A, Cdk2, Cdc2, p21 ${ }^{W A F 1 / C I P 1}$, Bax, and $\beta$-actin. (B) The same amounts of proteins of each sample were analyzed for caspase-3 (DEVDase) cleavage activity using cell-free protease assay as described under MATERIALS AND METHODS.

essential role in (or before) the step of mitochondrial permeability transition during apoptosis.

\section{Apoptotic progression induced by protein Bax is unaffected by blocking Cdk2 kinase activity}

Next, we examined whether Cdk2 kinase plays a role in regulating cell apoptosis after the mitochondrial release of cytochrome c. Ectopically expressed Bax localizes to mitochondria and provokes cytochrome c release from mitochondria into the cytosol, followed by caspase activation cascade (Oltvai et al., 1993; Rossé et al., 1998). We therefore co-transfected Bax with cyclin A, Cdk2-dn, p21 WAF1/CIP1, or $\mathrm{Bcl}-2$ (as a control) into HeLa cells and studied the effect of Cdk2 activity on the downstream events of cytochrome c release, including caspase- 3 activation and apoptotic morphology in transfected cells. The expression of Bax markedly induced caspase- 3 activity and simultaneous PARP cleavage as described previously (Rossé et al., 1998) (Fig. 5A and 5B). Interestingly, caspase activity and PARP cleavage were not affected in cells overexpressing Cdk2-dn, p21 WAF1/CIP1, or cyclin A (Fig. 5A and 5B). In contrast, overexpression of Bcl-2 as a positive control totally blocked caspase-3 activation and PARP cleavage in Bax-induced apoptotic cells. These results clearly showed that the Cdk2 kinase activity is not associated with the apoptotic process following mitochondrial release of cytochrome c.

Taken together, our results indicated that Cdk2 kinase plays an essential role in the mitochondrial stage of apoptosis by potentiating the mitochondrial permeability transition and 
thereby promoting cytochrome c release. However, Cdk2 kinase activity does not involve in the regulation of downstream apoptotic processes after the cytochrome $\mathrm{c}$ release.

\section{DISCUSSION}

Here, we provide evidence that upregulation of the Cdk2 kinase activity involves in the loss of MMP and thereby cytochrome c release, and therefore in the induction of apoptosis in paclitaxel-treated HeLa cells. We have described three major observations: (1) Cdk2 and Cdc2 kinase activities are upregulated in cells treated with paclitaxel. Cdk2 activation temporally coincides with the induction of apoptosis, while Cdc2 is active during both the cell cycle arrest and induction and progression of apoptosis; (2) paclitaxel-induced apoptosis is functionally linked to the loss of MMP and subsequent cytochrome $c$ release, thereby with the activation of the caspase cascade. The selective inhibition of cyclindependent protein kinase activity by the ectopic expression of Cdk2-dn, or p21 WAF1/CIP1, prevents the loss of MMP and cytochrome $c$ release in paclitaxel-induced cells and thereby staves off apoptotic cell death. Ectopically expressed cyclin A can markedly upregulate mitochondrial Bax. (3) Cdk2 activity is not associated with caspase activation and apoptosis progression following cytochrome $\mathrm{c}$ release induced by ectopic Bax.

The rapid upregulation of Cdk2 activity is functionally associated with the onset of apoptosis in several experimental systems, including growth factor-deprived human endothelial cells, irradiated lymphocytes, heat shocked cells, and dexamethasone-treated cells (Levkau et al., 1998; Hiromura et al., 2002; Choi et al., 2007). Thus, Cdk2, a key regulator of the cell cycle, has been suggested to play a role in apoptosis. In previous reports, we showed that the induction of cyclin A-Cdk2 activity, but not Cdc2 activity, is essential for the apoptotic progression of human hepatoma SK-HEP1 cells induced by ginsenoside Rh2 (Jin et al., 2000) and Panaxadiol (Jin et al., 2003). Other groups have shown that cyclin B-Cdc2 kinase activity is implicated in the paclitaxel-induced apoptosis of cells such as the human breast carcinoma cell line MCF-7 (Shen et al., 1998), the human cervical cell line HeLa cells (Donaldson et al., 1994), and the human hepatoma cell line HepG2 (Gagandeep et al., 1999). Here we show that both cyclin A-Cdk2 and cyclin B-Cdc2 kinase activities are upregulated in paclitaxel treated HeLa cells (Fig. 2). Cdc2 kinase activity is detectably up-regulated $3 \mathrm{~h}$ after treatment of the cells with paclitaxel and rises gradually thereafter until $27 \mathrm{~h}$ (Fig. 2B). In contrast, Cdk2 kinase activity after paclitaxel treatment exhibits a different profile of activation, rising gradually from $6 \mathrm{~h}$ to $15 \mathrm{~h}$ and then declining thereafter (Fig. 2C). It is notable that the time course of Cdc2 kinase activity coincides with all cellular responses, including cell cycle arrest, initiation and progression of apoptosis in paclitaxel treated HeLa cells. However, the upregulation of
Cdk2 kinase activity parallels only the initial stages of apoptosis. These kinetic profiles suggest that Cdk2 activity is involved in induction, but not in the progression of apoptosis. The overall levels of Cdk2 activity are much lower than those of Cdc2 activity during this period, which may explain why earlier studies did not detect the upregulation of Cdk2 kinase (Donaldson et al., 1994; Shen et al., 1998; Gagandeep et al., 1999). Moreover, the increases in Cdk2 and Cdc2 kinase activities reflect and are likely due in part to the elevated levels of cyclin A and cyclin B, respectively (Fig. 2B and 2C).

Importantly, the upregulation of these kinase activities is equally essential for the progression of apoptosis, as is demonstrated by the effects of cyclin-dependent kinase (CDK) inhibitors on apoptotic cell morphology. However, we mainly have studied the functional effect of Cdk2 kinase in paclitaxel-induced apoptosis. Apoptotic progression is markedly promoted in cells expressing cyclin $A$, while it is effectively prevented in cells expressing CDK2 inhibitors, Cdk2-dn, or p21 ${ }^{\text {WAF1/CIP1 }}$ (Fig. 3 and 4). In addition, apoptotic cell death induced by paclitaxel treatment is mediated primarily by the mitochondrion-dependent pathway, because apoptotic progression is effectively blocked in cells expressing Bcl-2. These results support earlier reports that activation of the Apaf-1-caspase-9 complex is the major pathway of apoptotic progression in paclitaxel-induced cells (André et al., 2000) and lead us to hypothesize that Cdk2 kinase can influence the apoptotic program in two ways. First, Cdk2 kinase may regulate apoptosis process by affecting the mitochondrial permeability transition with subsequent cytochrome $c$ release from mitochondria or before its upstream events. Second, these kinases may regulate apoptosome activity through phosphorylation of regulatory proteins, such as Apaf-1, IAPs, or caspase itself. To test this hypothesis, we co-transfected HeLa cells with pCMV-GFP and cyclin A, cdk2-dn, p21 ${ }^{W A F 1 / C I P 1}$ or Bcl-2. After treatment with paclitaxel, transfected cells were identified by GFP expression, and the mitochondrial membrane potential was monitored with the specific cationic dye Mitocapture, which accumulates in normal mitochondria, giving off a bright red fluorescence, but remains in the cytoplasm in monomeric form in cells with an altered mitochondrial membrane potential. Paclitaxelinduced depolarization is markedly promoted in cells expressing cyclin A, while it is effectively prevented in cells expressing CDK2 inhibitor proteins Cdk2-dn, or p2 $1^{W A F 1 / C I P 1}$, or in cells expressing Bcl-2 protein. Our data show that $42 \%$ of mock-transfected cells expressing GFP underwent mitochondrial depolarization after treatment with paclitaxel, while $59 \%$ of treated cells expressing cyclin A went to depolarization. In contrast, between $90 \%$ and $97 \%$ of cells expressing CDK2 inhibitor proteins did not undergo depolarization nor exhibited changes in apoptotic cell morphology after paclitaxel treatment (Fig. 4A and 4B). Moreover, mitochondrial Bax upregulation and cytochrome $c$ release 
was markedly enhanced in cells expressing cyclin A, while it was significantly suppressed in cells expressing CDK inhibitor proteins as indicated by decreases in the ratio of cytochrome $\mathrm{c} / \beta$-actin and mitochondrial Bax (Fig. 4C-E). Moreover, we observed minimal release of cytochrome $c$ in paclitaxel-treated transfectants expressing Cdk2-dn or p2 $1^{W A F 1 / C I P 1}$, because these cells were contaminated with a few number of untransfected cells. These results therefore suggest that upregulation of Cdk2 kinase activity is essential for the induction of mitochondrial permeability transition and consequent release of cytochrome c.

Then we addressed the possibility that Cdk2 kinase also regulates apoptotic events that occur after the release of cytochrome $\mathrm{c}$. We conducted a complementary experiment to induce apoptosis by triggering cytochrome c release from the mitochondria and provoking the events that occur after cytochrome c release without influencing upstream events. Earlier reports have shown that ectopic expression of Bax, a proapoptotic member of the $\mathrm{Bcl}-2$ family, triggers apoptosis by inducing cytochrome $\mathrm{c}$ release from the mitochondria (Oltvai et al., 1993; Rossé et al., 1998). This system includes all apoptotic processes occurring after the mitochondrial event including apoptosome formation, caspase 9 autoactivation, and downstream effector caspase activation. Our results clearly demonstrate that apoptotic progression, as indicated by an increase in caspase- 3 activity and thereby in PARP cleavage in this system, is not influenced by overexpression of Cdk2 kinase inhibitors Cdk2-dn, and p21 WAF1/CIP1, or a Cdk2 kinase activating protein, cyclin A (Fig. 5A-D). In contrast, Bax-induced apoptosis is completely prevented in cells that overexpress Bcl-2. Thus, these increases in Cdk2 kinase activity cannot influence downstream processes that occur after the mitochondrial release of cytochrome c.

Based on the collective evidence, we propose that the Cdk2 kinase plays essential roles in the induction of apoptosis before or in the mitochondrial permeability transition, but does not influence events that occur following the release of cytochrome $c$ in HeLa cells after treatment with paclitaxel.

\section{MATERIALS AND METHODS}

\section{Materials}

Paclitaxel was obtained from Sigma. Dulbecco's Modified Eagle's Medium and calf serum were from Life Technologies, Inc. General chemicals were purchased from Sigma. [ $\left.\mathrm{Y}^{-}{ }^{32} \mathrm{P}\right] \mathrm{ATP}$ was purchased from Amersham Pharmacia Biotech.

Tissue culture methods, and induction and analysis of apoptosis in cultured cells

HeLa cells were maintained as a monolayer culture in Dulbecco's modified Eagle's medium supplemented with 5\% ( $/ v)$ heat-inacti- vated calf serum, $100 \mathrm{U} / \mathrm{mL}$ penicillin, and $100 \mu \mathrm{g} / \mathrm{mL}$ streptomycin. Paclitaxel was added to a final concentration of $80 \mathrm{nmol} / \mathrm{L}$ to $\mathrm{log}$ phase cell cultures for indicated time periods. Both floating and adherent cells were harvested for immunoblot experiments and histone $\mathrm{H} 1$ kinase assays. At the same time, another set of paclitaxeltreated cells was harvested by trypsinization, washed once with PBS, fixed in $100 \%$ ethanol, and stained with DAPI solution (Partec, Germany). Cell cycle profiles were determined with a flow cytometer (PAS-III, Partec, Germany) and analyzed using WinMDI software.

\section{Transient transfections and analysis of apoptosis in transfected} cells

HeLa cells $\left(2 \times 10^{5}\right)$ were co-transfected with $0.5 \mu \mathrm{g}$ pCMV-GFP and $1.5 \mu \mathrm{g}$ pCMV-cyclin A, pCMV-cdk2-dn, pCMV-cdc2, or pCMVp21 WAF1/CIP1 using $15 \mu \mathrm{L}$ Polyfect (Qiagen) as specified by the manufacturer. Apoptosis was induced $24 \mathrm{~h}$ later by the addition of paclitaxel to $80 \mathrm{nmol} / \mathrm{L}$. After treatment for $10,14,18$ or $24 \mathrm{~h}$, cells were examined by fluorescence microscopy (Olympus). The extent of apoptosis was determined by counting GFP-expressing cells with blebbing or normal morphology in about 20 randomly selected fields (20-30 cells per field).

\section{Immunoblot analysis}

Cells were washed with ice-cold phosphate-buffered saline and solubilized in immunoprecipitation lysis buffer containing $20 \mathrm{mmol} / \mathrm{L}$ Tris, $\mathrm{pH} 7.5,0.5 \%$ Triton X-100, $2 \mathrm{mmol} / \mathrm{L} \mathrm{MgCl}_{2}, 1 \mathrm{mmol} / \mathrm{L}$ dithiothreitol, $1 \mathrm{mmol} / \mathrm{L}$ EGTA, $50 \mathrm{mmol} / \mathrm{L} \beta$-glycerol phosphate, $25 \mathrm{mmol} / \mathrm{L} \mathrm{NaF}, 1 \mathrm{mmol} / \mathrm{L} \mathrm{Na} \mathrm{VO}_{4}, 2 \mu \mathrm{g} / \mathrm{mL}$ leupeptin, $2 \mu \mathrm{g} / \mathrm{mL}$ pepstatin $A, 2 \mu \mathrm{g} / \mathrm{mL}$ antipain, and $1 \mathrm{mmol} / \mathrm{L}$ phenylmethylsulfonyl fluoride (PMSF). After incubation on ice for $1 \mathrm{~h}$, the insoluble materials were removed by centrifugation at $12,000 \mathrm{~g}$ for $15 \mathrm{~min}$. An aliquot ( $30 \mu \mathrm{g}$ of protein) from each sample was resolved by SDSpolyacrylamide gel electrophoresis (SDS-PAGE) and electro-transferred onto a polyvinylidene difluoride membrane (Gelman). The membrane was blocked with $5 \%$ nonfat milk and probed with anticyclin A, -cyclin B, -cyclin E, or- $\beta$-actin antibodies (Santa Cruz Biotechnology), or with polyclonal rabbit antibodies (Santa Cruz Biotechnology) to Cdk2 (raised against the C-terminal peptide of Cdk2), Cdc2, or polyadenylribosyl polymerase (PARP). The blots were washed, incubated with horseradish peroxidase-coupled antimouse IgG or anti-rabbit IgG (Pierce) and visualized by ECL (Amersham Pharmacia Biotech).

\section{Immunoprecipitation and histone $\mathrm{H} 1$ kinase assay}

An aliquot (200 $\mu \mathrm{g}$ protein) from each cell extract was precleared with protein A-agarose beads (Upstate Biotechnology, Inc.), and the supernatant was incubated with polyclonal rabbit antibodies to Cdc2 or Cdk2 for $4 \mathrm{~h}$. Immune complexes associated with Cdc2 or Cdk2 were collected after incubating with protein A-agarose beads for $2 \mathrm{~h}$. The immune complexes were washed three times with immunoprecipitation lysis buffer and twice with kinase assay buffer containing $50 \mathrm{mmol} / \mathrm{L}$ Tris, $\mathrm{pH} 7.5,10 \mathrm{mmol} / \mathrm{L} \mathrm{MgCl}_{2}, 1 \mathrm{mmol} / \mathrm{L}$ dithiothreitol, $1 \mathrm{mmol} / \mathrm{L}$ EGTA, $50 \mathrm{mmol} / \mathrm{L} \beta$-glycerol phosphate, $25 \mathrm{mmol} / \mathrm{L} \mathrm{NaF}$, $0.1 \mathrm{mmol} / \mathrm{L} \mathrm{Na}_{3} \mathrm{VO}_{4}, 1 \mu \mathrm{g} / \mathrm{mL}$ leupeptin, $1 \mu \mathrm{g} / \mathrm{mL}$ pepstatin $\mathrm{A}, 1 \mu \mathrm{g} / \mathrm{mL}$ anti pain, and $1 \mathrm{mmol} / \mathrm{L} \mathrm{PMSF}$. The immune complexes were 
incubated for $15 \mathrm{~min}$ at $30^{\circ} \mathrm{C}$ in $50 \mu \mathrm{L}$ kinase assay buffer supplemented with $5 \mu \mathrm{g}$ histone $\mathrm{H} 1$ (Life Technologies, Inc.), $10 \mu \mathrm{Ci}$ [ $\left.\mathrm{\gamma}^{32}{ }^{32} \mathrm{P}\right] \mathrm{ATP}(10 \mu \mathrm{M}), 5 \mu \mathrm{mol} / \mathrm{L}$ protein kinase A inhibitor, and $20 \mathrm{mmol} /$ L EGTA, and the proteins were resolved by $12 \%$ SDS-PAGE. Cdc2 and Cdk2 kinase activities were determined by autoradiography.

\section{Caspase activity assay}

$50 \mu \mathrm{g}$ cell lysate protein was incubated in $100 \mu \mathrm{L}$ reaction buffer (20 mmol/L HEPES, pH 7.4, $100 \mathrm{mmol} / \mathrm{L} \mathrm{NaCl}, 10 \mathrm{mmol} / \mathrm{L}$ DTT, $0.1 \%$ CHAPS, $10 \%$ sucrose) containing $25 \mu \mathrm{mol} / \mathrm{L}$ of the caspase- 3 substrate acetyl-Asp-Glu-Val-Asp-7-amino-4 methylcoumarin (AcDEVD-AFC) in a 96-well microtiter plate. Lysates were incubated for $1 \mathrm{~h}$, and cleaved substrate fluorescence levels were determined using a SpectraFluor F129003 (Tecan) with excitation and emission wavelengths of $405 \mathrm{~nm}$ and $465 \mathrm{~nm}$, respectively.

\section{Cytosolic protein extract preparation and cytochrome c release assay}

Cytosolic protein extracts were prepared as previously described (Rossé et al., 1998). Briefly, paclitaxel-treated cells were washed twice with PBS and cell pellets were resuspended in $500 \mu \mathrm{L}$ ice-cold buffer containing $10 \mathrm{mmol} / \mathrm{L}$ HEPES, $\mathrm{pH} 7.4,1 \mathrm{mmol} / \mathrm{L}$ EDTA, $0.25 \mathrm{~mol} / \mathrm{L}$ sucrose, $2 \mu \mathrm{g} / \mathrm{mL}$ leupeptin, $1 \mu \mathrm{g} / \mathrm{mL}$ pepstatin $A$, $1 \mathrm{mmol} / \mathrm{L}$ PMSF, and disrupted by homogenization using a Dounce homogenizer. The lysates were centrifuged at $10,000 \times \mathrm{g}$ for $1 \mathrm{~h}$ and equal amounts of the supernatant (cytosolic fraction) were subjected to immunoblot analysis using mouse monoclonal anti-cytochrome $\mathrm{c}$ (Pharmingen) antibodies.

\section{Mitochondrial protein extract preparation and immunoblot analysis}

Mitochondrial protein extracts were prepared using a Mitochondrion Isolation Kit (Pierce) according to the manufacturer's instructions. Isolated mitochondria were solubilized in a lysis buffer containing $20 \mathrm{mmol} / \mathrm{L}$ Tris- $\mathrm{HCl}(\mathrm{pH} 7.5), 150 \mathrm{mmol} / \mathrm{L} \mathrm{NaCl}, 1 \% \mathrm{NP}-40,0.5 \%$ deoxycholate, $0.1 \%$ SDS, $2 \mathrm{mmol} / \mathrm{L} \mathrm{MgCl}_{2}, 1 \mathrm{mmol} / \mathrm{L} \mathrm{DTT}, 1 \mathrm{mmol} / \mathrm{L}$ EGTA, $50 \mathrm{mmol} / \mathrm{L}$ - -glycerol phosphate, $25 \mathrm{mmol} / \mathrm{L} \mathrm{NaF}, 1 \mathrm{mmol} / \mathrm{L}$ $\mathrm{Na}_{3} \mathrm{VO}_{4}, 2 \mu \mathrm{g} / \mathrm{mL}$ leupeptin, $2 \mu \mathrm{g} / \mathrm{mL}$ pepstatin $\mathrm{A}, 2 \mu \mathrm{g} / \mathrm{mL}$ antipain, and $1 \mathrm{mmol} / \mathrm{L}$ PMSF. The mitochondrial proteins were then subjected to immunoblotting analysis using antibodies against $\mathrm{Bax}, \mathrm{Bcl}-2, \mathrm{Cdk} 2$, Cyclin A and COX IV (Santa Cruz Biotechnology).

\section{Mitochondrial membrane depolarization assay}

Cells were incubated with $1 \mu \mathrm{g} / \mathrm{mL}$ MitoCapture cation dye (Calbiochem) for $30 \mathrm{~min}$ at $37^{\circ} \mathrm{C}$ and photographed under a fluorescence microscope (Olympus) with excitation wavelengths at $500 \mathrm{~nm}$ and $570 \mathrm{~nm}$, respectively.

\section{ACKNOWLEDGEMENTS}

This work was supported by the National Natural Science Foundation of China (Grant Nos. 90813003 and 31070670 ) and by a grant from the National Research Laboratory Fund (M10104000129-02J0000-
05910) from the Ministry of Science and Technology, Korea, to S. K. Lee.

\section{ABBREVIATIONS}

Cdk2, cyclin-dependent kinase 2; Cdk2-dn, dominant negative version of Cdk2; MMP, mitochondrial membrane potential; PARP, poly(ADP-ribosyl) polymerase

\section{REFERENCES}

André, N., Braguer, D., Brasseur, G., Gonçalves, A., LemesleMeunier, D., Guise, S., Jordan, M.A., and Briand, C. (2000). Paclitaxel induces release of cytochrome $c$ from mitochondria isolated from human neuroblastoma cells'. Cancer Res 60, 5349-5353.

Bruce, A., Edgar, T.L., and Terry, L.O. (2001). Endoreplication cell cycles: more for less. Cell 105, 297-306.

Bastin-Coyette, L., Cardoen, S., Smal, C., de Viron, E., Arts, A., Amsailale, R., Van Den Neste, E., and Bontemps, F. (2011). Nucleoside analogs induce proteasomal down-regulation of p21 in chronic lymphocytic leukemia cell lines. Biochem Pharmacol 81, 586-593.

Beere, H.M., Wolf, B.B., Cain, K., Mosser, D.D., Mahboubi, A., Kuwana, T., Tailor, P., Morimoto, R.I., Cohen, G.M., and Green, D. R. (2000). Heat-shock protein 70 inhibits apoptosis by preventing recruitment of procaspase- 9 to the Apaf- 1 apoptosome. Nat Cell Biol 2, 469- 475.

Breckenridge, D.G., and Xue, D. (2004). Regulation of mitochondrial membrane permeabilization by BCL-2 family proteins and caspases. Curr Opin Cell Biol 16, 647-652.

Caroppi, P., Sinibaldi, F., Fiorucci, L., and Santucci, R. (2009). Apoptosis and human diseases: mitochondrion damage and lethal role of released cytochrome $\mathrm{C}$ as proapoptotic protein. Curr Med Chem 16, 4058-4065.

Chipuk, J.E., and Green, D.R. (2008). How do BCL-2 proteins induce mitochondrial outer membrane permeabilization? Trends Cell Biol 18, 157-164.

Chang, H., and Schimmer, A.D. (2007). Livin/melanoma inhibitor of apoptosis protein as a potential therapeutic target for the treatment of malignancy. Mol Cancer Ther 6, 24-30.

Choi, J.S., Shin, S., Jin, Y.H., Yim, H., Koo, K.T., Chun, K.H., Oh, Y.T., Lee, W.H., and Lee, S.K. (2007). Cyclin-dependent protein kinase 2 activity is required for mitochondrial translocation of Bax and disruption of mitochondrial transmembrane potential during etoposide-induced apoptosis. Apoptosis 12, 1229-1241.

Djeu, J.Y., and Wei, S. (2009). Clusterin and chemoresistance. Adv Cancer Res 105, 77-92.

Donaldson, K.L., Goolsby, G.L., Kiener, P.A., and Wahl, A.F. (1994). Activation of $\mathrm{p} 34 \mathrm{cdc} 2$ coincident with taxol-induced apoptosis. Cell Growth Differ 5, 1041-1050.

Du, C., Fang, M., Li, Y., Li, L., and Wang, X. (2000). Smac, a mitochondrial protein that promotes cytochrome c-dependent caspase activation by eliminating IAP inhibition. Cell 102, 33-42.

Gagandeep, S., Novikoff, P.M., Ott, M., and Gupta, S. (1999). Paclitaxel shows cytotoxic activity in human hepatocellular carcinoma cell lines. Cancer Lett 136, 109-118. 
Garrido, C., Galluzzi, L., Brunet, M., Puig, P.E., Didelot, C., and Kroemer, G. (2006). Mechanisms of cytochrome c release from mitochondria. Cell Death Differ 13, 1423-1433.

Hiromura, K., Pippin, J.W., Blonski, M.J., Roberts, J.M., and Shankland, S.J. (2002). The subcellular localization of cyclin dependent kinase 2 determines the fate of mesangial cells: role in apoptosis and proliferation. Oncogene 21, 1750-1758.

Hunt, J.T. (2009). Discovery of ixabepilone. Mol Cancer Ther 8, 275-281.

Jin, Y.H., Yim, H., Park, J.H., and Lee, S.K. (2003). Cdk2 activity is associated with depolarization of mitochondrial membrane potential during apoptosis. Biochem Biophys Res Commun 305, 974-980.

Jin, Y.H., Yoo, K.J., Lee, Y.H., and Lee, S.K. (2000). Caspase 3mediated cleavage of $\mathrm{p} 21^{\text {WAF } 1 / C I P 1}$ associated with the cyclin Acyclin-dependent kinase 2 complex is a prerequisite for apoptosis in SK-HEP-1 cells. J Biol Chem 275, 30256-30263.

Kaldis, P., and Aleem, E. (2005). Cell cycle control sibling rivalry: Cdc2 vs. Cdk2 Cell Cycle 4, 1491-1494.

Levkau, B., Koyama, H., Raines, E.W., Clurman, B.E., Herren, B., Orth, K., Roberts, J.M., and Ross, R. (1998). Cleavage of $\mathrm{p} 21^{\mathrm{WAF} 1 / \mathrm{CIP} 1}$ and $\mathrm{p} 27^{\mathrm{KIP} 1}$ mediates apoptosis in endothelial cells through activation of Cdk2: role of a caspase cascade. Mol Cell 1, 553-563.

Li, K., Li, Y., Shelton, J.M., Richardson, J.A., Spencer, E., Chen, Z.J., Wang, X., and Williams, R.S. (2000). Cytochrome c deficiency causes embryonic lethality and attenuates stress-induced apoptosis. Cell 101, 389-399.

Ling, Y.H., Tornos, C., and Perez-Soler, R. (1998). Phosphorylation of $\mathrm{Bcl}-2$ is a marker of $\mathrm{M}$ phase events and not a determinant of apoptosis. J Biol Chem 273, 18984-18991.

Liston, P., Fong, W.G., and Korneluk, R.G. (2003). The inhibitors of apoptosis: there is more to life than Bcl2. Oncogene 22, 8568-8580.

Marupudi, N.I., Han, J.E., Li, K.W., Renard, V.M., Tyler, B.M., and Brem, H. (2007). Paclitaxel: a review of adverse toxicities and novel delivery strategies. Expert Opin Drug Saf 6, 609-621.

Matthess, Y., Raab, M., Sanhaji, M., Lavrik, I.N., and Strebhardt, K. (2010). Cdk1/cyclin B1 controls Fas-mediated apoptosis by regulating caspase-8 activity. Mol Cell Biol 30, 5726-5740.

Oltvai, Z.N., Milliman, C.L., and Korsmeyer, S.J. (1993). Bcl-2 heterodimerizes in vivo with a conserved homolog, Bax, that accelerates programmed cell death. Cell 74, 609-619.

Pandey, P., Saleh, A., Nakazawa, A., Kumar, S., Srinivasula, S.M.,
Kumar, V., Weichselbaum, R., Nalin, C., Alnemri, E.S., Kufe, D., et al. (2000). Negative regulation of cytochrome c-mediated oligomerization of Apaf-1 and activation of procaspase-9 by heat shock protein 90. EMBO J 19, 4310-4322.

Placzek, W.J., Wei, J., Kitada, S., Zhai, D., Reed, J.C., and Pellecchia, M. (2010). A survey of the anti-apoptotic Bcl-2 subfamily expression in cancer types provides a platform to predict the efficacy of Bcl-2 antagonists in cancer therapy. Cell Death Dis 1, e40.

Pradelli, L.A., Bénéteau, M., and Ricci, J.E. (2010). Mitochondrial control of caspase-dependent and -independent cell death. Cell Mol Life Sci 67, 1589-1597.

Riedl, S.J., and Shi, Y. (2004). Molecular mechanisms of caspase regulation during apoptosis. Nat Rev Mol Cell Biol 5, 897-907.

Rossé, T., Olivier, R., Monney, L., Rager, M., Conus, S., Fellay, I., Jansen, B., and Borner, C. (1998). Bcl-2 prolongs cell survival after Bax-induced release of cytochrome c. Nature 391, 496-499.

Rowinsky, E.K., and Donehower, R.C. (1995). Paclitaxel (taxol). N Engl J Med 332, 1004-1014. PMID:7885406Saleh, A., Srinivasula, S.M., Balkir, L., Robbins, P.D., and Alnemri, E.S. (2000). Negative regulation of the Apaf-1 apoptosome by Hsp70. Nat Cell Biol 2, 476- 483.

Salvesen, G.S., and Dixit, V.M. (1999). Caspase activation: the induced-proximity model. Proc Natl Acad Sci U S A 96, 10964-10967.

Schiff, P.B., Fant, J., and Horwitz, S.B. (1979). Promotion of microtubule assembly in vitro by taxol. Nature 277, 665-667.

Shen, S.C., Huang, T.S., Jee, S.H., and Kuo, M.L. (1998). Taxolinduced p34cdc2 kinase activation and apoptosis inhibited by 12 O-tetradecanoylphorbol-13-acetate in human breast MCF-7 carcinoma cells. Cell Growth Differ 9, 23-29.

Shi, Y. (2002). Mechanisms of caspase activation and inhibition during apoptosis. Mol Cell 9, 459-470.

Stewart, Z.A., Mays, D., and Pietenpol, J.A. (1999). Defective G1-S cell cycle checkpoint function sensitizes cells to microtubule inhibitor-induced apoptosis. Cancer Res 59, 3831-3837.

Willis, S.N., and Adams, J.M. (2005). Life in the balance: how BH3only proteins induce apoptosis. Curr Opin Cell Biol 17, 617-625.

Wu, H., Tschopp, J., and Lin, S.C. (2007). Smac mimetics and TNFalpha: a dangerous liaison? Cell 131, 655-658.

Zhou, B.B., Li, H., Yuan, J., and Kirschner, M.W. (1998). Caspasedependent activation of cyclin-dependent kinases during Fasinduced apoptosis in Jurkat cells. Proc Natl Acad Sci U S A 95, 6785-6790. 